Article

\title{
Retinal Nerve Fiber Layer in Patients with Alcohol Use Disorder
}

\author{
Sonia Álvarez-Sesmero ${ }^{1}\left(\mathbb{D}\right.$, Francisco J. Povedano-Montero ${ }^{2,3,4}{ }^{\circledR}$, Francisco Arias-Horcajadas ${ }^{1}$, \\ Marta Marín-Mayor ${ }^{1}$, Patricia Navarrete-Chamorro ${ }^{3}{ }^{\mathbb{D}}$, Isidoro Raga-Martínez ${ }^{5}$, \\ Gabriel Rubio ${ }^{1,4,6}$ and Francisco López-Muñoz ${ }^{4,5,6,7, *(D)}$ \\ 1 Department of Psychiatry, Hospital Universitario Doce de Octubre, 28041 Madrid, Spain; \\ sasesmero@salud.madrid.org (S.Á.-S.); francisco.arias@salud.madrid.org (F.A.-H.); \\ marta.marin@salud.madrid.org (M.M.-M.); grubiovalladolid@gmail.com (G.R.) \\ 2 Faculty of Optics and Optometry, Complutense University, 28040 Madrid, Spain; grupocom6@gmail.com \\ Centro Óptico Montero, 28032 Madrid, Spain; p.navarrete.ch@hotmail.com \\ Hospital Doce de Octubre Research Institute (i+12), 28041 Madrid, Spain \\ 5 Faculty of Health Sciences, University Camilo José Cela, 28692 Madrid, Spain; ijraga@cnoo.es \\ 6 Thematic Network for Cooperative Health Research (RETICS), Addictive Disorders Network, \\ Health Institute Carlos III, MICINN and FEDER, 28029 Madrid, Spain \\ 7 Portucalense Institute of Neuropsychology and Cognitive and Behavioural Neurosciences (INPP), \\ Portucalense University, 4200072 Porto, Portugal \\ * Correspondence: flopez@ucjc.edu; Tel.:+34-91-815-3131
}

Received: 1 October 2019; Accepted: 2 December 2019; Published: 6 December 2019

\begin{abstract}
The objectives of the present study are to determine the effects of alcohol use on the retinal nerve fiber layer (RNFL) thickness and macular thickness of abstinent patients with alcohol use disorders (AUD) and to assess whether it correlates with alcohol consumption and/or cognitive impairment. This was a prospective, observational study that included 21 patients (42 eyes) and 21 controls (42 eyes). Patients met the criteria for early remission AUD at the moment of inclusion. We used optical coherence tomography to assess retinal thickness. Macular thickness in the group of AUD patients was lower in all quadrants $(p<0.05)$, with the exception of the peripheral and central. Regarding the nerve fiber layer in the macular and papilla areas, we found no significant differences. At the retina ganglion cell layer and in the nerve fiber of the macula, we found significant differences in all quadrants $(p<0.05)$, with the exception of the superior and superior nasal area, for the right eye. For the left eye, the only differences were found in the lower quadrant. Finally, when comparing the AUD patients to the controls, we found significant reductions in the ganglion cell layer of the macula in all quadrants in the former. There was a significant correlation between these findings and cognitive impairment (measured with the Test de Detección de Deterioro Cognitivo en Alcoholismo (TEDCA)), but not with alcohol consumption. Alcohol consumption is correlated with retinal harm and related cognitive decline.
\end{abstract}

Keywords: retina; alcohol; optical coherence tomography; mental disorder

\section{Introduction}

Excessive alcohol consumption currently constitutes a huge, worldwide social health issue. The latest health report of the World Health Organization (WHO) published in 2018 [1] highlighted that 3.1 billion people worldwide had consumed alcohol in the last year, 2.1 billion of whom were regular consumers. In addition, in 2016 harmful alcohol use caused approximately 3 million deaths worldwide $(5.3 \%)$, reaching even higher rates than deaths caused by diabetes, HIV/AIDS, and tuberculosis [1]. 
There is evidence that alcohol consumption impairs the central nervous system (CNS) [2,3]. However, no routine techniques are used to asses this impairment in patients with alcohol consumption. This is due to their complexity and high costs.

The retina is an accessible area of the CNS for the purposes of clinical examination, and for this reason it is considered a "brain window" [4]. It has been proposed that optical coherence tomography (OCT) is a non-invasive technique for assessing retinal impairment caused by several substances, such as cocaine, and at the same time, it has been correlated with brain atrophy [5]. Some authors, such as Schwitzer et al. [6], have postulated that changes observed in the retina could reflect changes in the brain tissue, and in this way, it could constitute an accessible marker for evaluating CNS impairment. Several studies have been published in which OCT has been used to assess CNS impairment in neurological diseases such as Parkinson's disease or multiple sclerosis. However, there is little research regarding mental illnesses and the results are controversial [7].

Due to the high level of alcohol consumption worldwide and the neurotoxicity caused by alcohol, we aimed to carry out a study on abstinent alcoholic patients who met the criteria for alcohol use disorders (AUD). Our first objective was to determine the harmful effects of alcohol consumption on the retina. Secondly, we aimed to assess whether this impairment could correlate with alcohol consumption and the associated cognitive impairment.

\section{Materials and Methods}

\subsection{Study Sample}

This was an observational, prospective study, in which 21 patients over the age of 18 (42 eyes in total) and 21 healthy controls were paired by age. The patients included had met the DSM- 5 criteria for AUD for at least 5 continuous years and had been abstinent for at least 3 months. In both groups, participants were Caucasian. The patients were recruited from the Relapse Prevention and Social Skills therapy groups provided by the Alcoholism Unit at the "12 de Octubre University Hospital". These psychotherapeutic groups are offered to patients who have already completed the alcohol detoxification phase, and they focus on the acquisition of skills to detect and prevent relapses in the first stage. In a second stage, they intend to focus on other different skills, such as anxiety, anger or guilt management, which can be associated with relapse in alcohol consumption.

Exclusion criteria were active consumption of alcohol or other substances (with the exception of nicotine) and meeting diagnostic criteria for cognitive impairment. Other ophthalmological exclusion criteria were as follows: suffering from previous retinopathy, ocular hypertension (>18 $\mathrm{mg} \mathrm{Hg}$ ), and history of glaucoma, cataracts, or ocular surgery.

Each participant was informed about the study and signed informed consent before inclusion. A standard ophthalmological exam, including refractive error determination and best corrected visual acuity, as well as eye examination and assessment of ocular pressure with air-puff tonometry, were carried out. After having obtained these test results, those participants who did not suffer from any ophthalmological condition listed in the exclusion criteria were included in our study. The cut-off for exclusion based on refraction refractive error was \pm 5 diopters.

\subsection{Procedures}

The recommendations of the nine-point advised protocol for OCT study terminology and elements (Advised Protocol for OCT Study Terminology and Elements (APOSTEL)) was applied for the study design. The SD-OCT (spectral domain optical coherence tomography) imaging was performed using the Topcon 3D OCT-1 Maestro II, Topcon GB (firmware version 1.27, Topcon Medical Systems Tokyo, Japan). The instrument captures 50,000 axial scans per second. The device simultaneously captures the macula and optic nerve head areas, giving both a digital fundus image and a $12 \times 9 \mathrm{~mm}$ automated segmentation OCT scan ("wide scan" setting). The device produces $20 \mu \mathrm{m}$ lateral and $6 \mu \mathrm{m}$ axial resolutions. Both eyes of each patient and control subject were examined. According to the instrumental 
protocol, 3D macula and 3D wide maps were used for the study of the macula and the peripapillary retinal nerve fiber, respectively.

The SD-OCT imaging was carried out by the same examiner (F.J.P-M) during the morning hours, in a dark room, using the 3-dimensional $6 \times 6 \mathrm{~mm}^{2}$ macular volume scan mode (512 A scans per B scan; 128 horizontal B scan) in a raster pattern.

For all scans, patients were asked to fixate on an internal target. The optic disk was clearly visualized, and the scan was centered on the optic disk. To assess peripapillary retinal nerve fiber layer (RNFL) thickness, we used a circular scan, $12^{\circ}$ in diameter, centered on the optic disc with optic nerve fiber layer modality and 100 frames averaged for each scan. The RNFL thickness in each of the $90^{\circ}$ quadrants (superior, inferior, temporal, and nasal) around the optic disc of both left and right eyes (Figure 1) was obtained using the software Topcon Advanced Boundary Segmentation (TABSTM). The analysis report also provided a description of which percentile ( $\leq 95$ th to $>5$ th, normal), ( $\leq 5$ th to 1 st, borderline), and ( $<1$ st, abnormal) the RNFL thickness fell into, based on the manufacturer's database of age-corrected normal values.

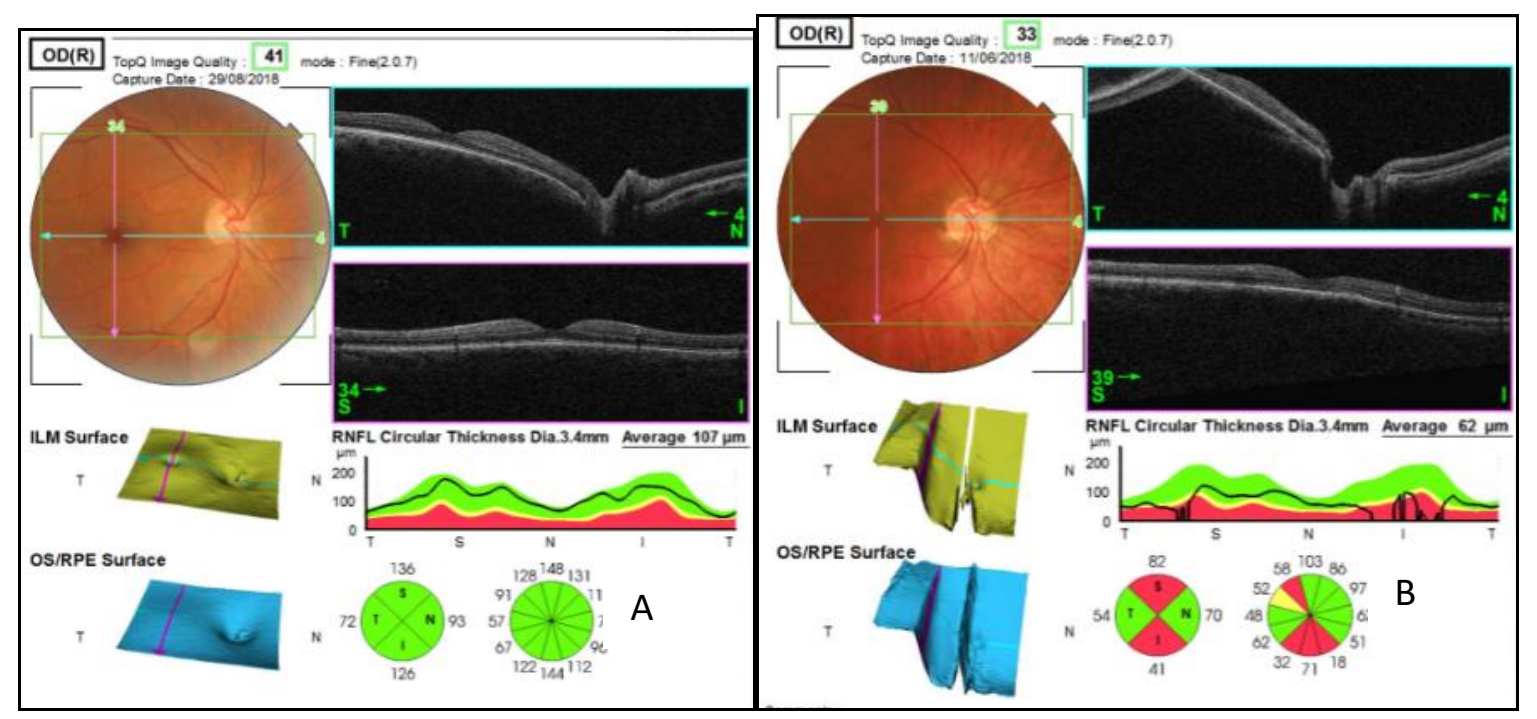

Figure 1. Right-eye sample optical coherence tomography (OCT) of peripapillary retinal nerve fiber layer (RNFL) thickness. Right-eye sample OCT of peripapillary RNFL thickness was taken from a healthy control (A), showing normal RNFL thickness with an average RNFL thickness of $107 \mu \mathrm{m}$, and from an alcohol use disorder (AUD) patient (B), with an average RNFL thickness of $62 \mu \mathrm{m}$. The RNFL thickness in the superior and inferior quadrants is shown in red, as the measurements fall between the 5 th and the 1st percentile of the normal distribution percentiles provided by the manufacturer's internal database. The RNFL thickness in each of the $90^{\circ}$ quadrants is shown in green, as the measurements fall within the $\leq 95$ th to $\geq 5$ th percentile of the normal distribution percentiles provided by the manufacturer's internal database (for interpretation of the references to color in this figure legend, the reader is referred to the web version of this article).

The following parameters, automatically measured by the OCT software, were also obtained for each eye: central retinal thickness, central macular thickness, macular RNFL (Figure 2), and ganglion cell layer (GCL) thickness in each of the $90^{\circ}$ quadrants (Figure 3). For the study of the GLC, we have divided the analysis into the complete layer (GCC), which includes from inner limiting membrane (ILM) to the inner plexiform layer (IPL), which we called GLC ++ , and the ganglion cell layer, which includes GCL and IPL (GCIP), which we called GLC+ (Figure 4). 


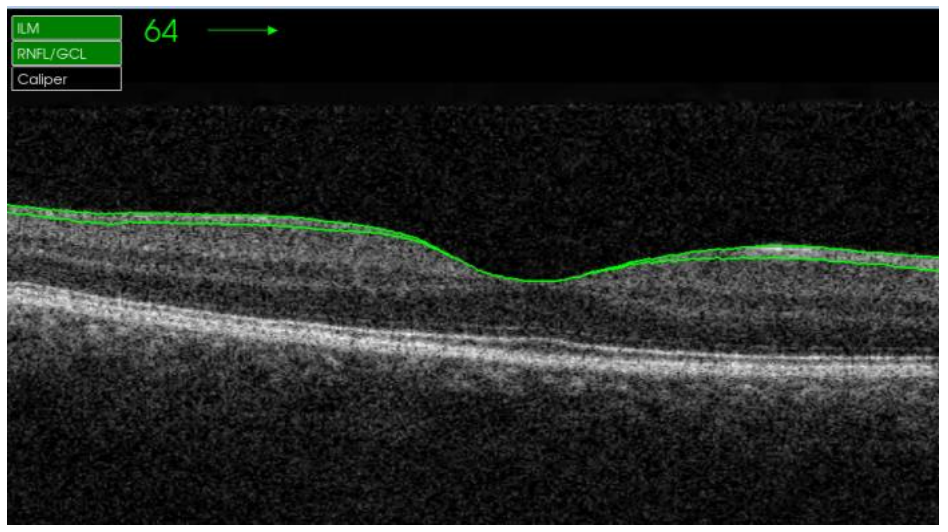

Figure 2. Segmentation of intra-retinal layers in the macula.
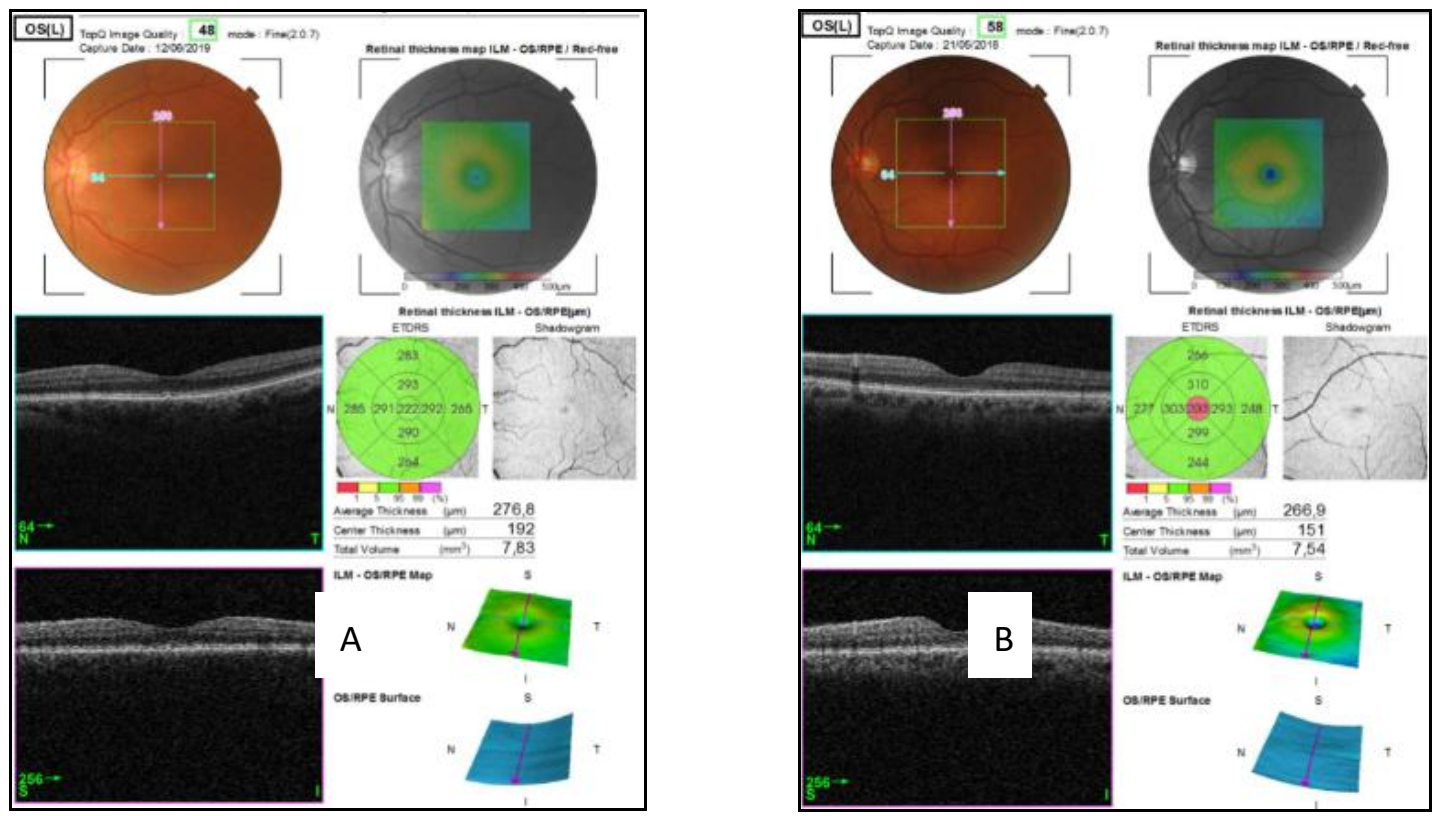

Figure 3. Left-eye sample OCT of central retinal thickness and central macular thickness. Left-eye sample optical coherence tomography of retina central thickness was taken from a healthy control (A), showing normal central thickness with an average thickness of $192 \mu \mathrm{m}$, and from an AUD patient (B), with an average central thickness of $151 \mu \mathrm{m}$.

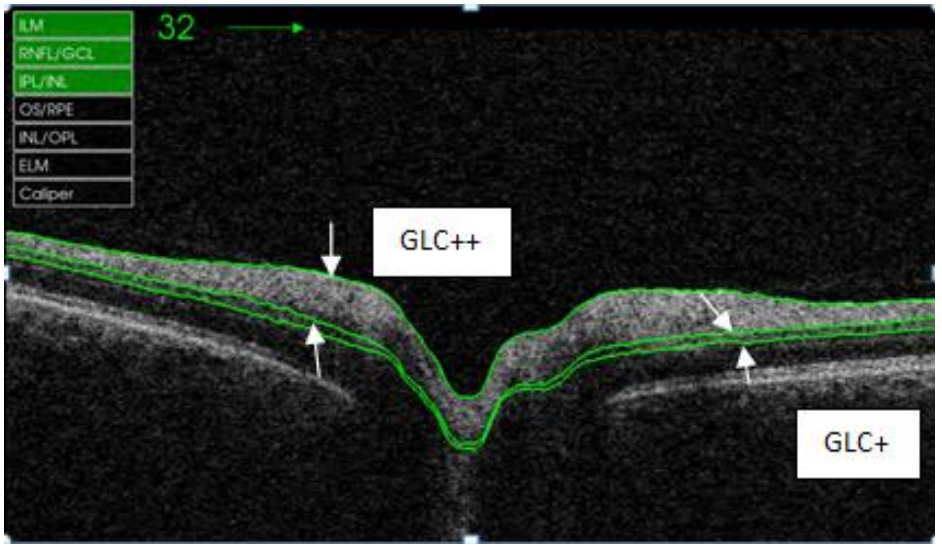

Figure 4. Segmentation of intra-retinal layers in optic nerve. 
Scans were assessed for their quality and were excluded if they were off-center or had significant movement artefacts. Another additional factor that was taken into account was the image quality value (IQV), which is a standard characteristic of Topcon that assigns a quantitative value to the quality of the obtained image. A value equal to or greater than 30 is considered to be an image with sufficient quality for the final analysis.

The right eye was imaged first, and this scan was repeated for the left eye. We were successful in obtaining scans on both eyes without mydriasis in all participants.

All the patients' histories of alcohol consumption were recorded through a clinical interview, and alcohol consumption was unified using the standard drinking unit (SDU).

In order to assess cognitive impairment associated with alcohol consumption, we used the Cognitive Impairment in Alcoholic Population Test (Test de Detección de Deterioro Cognitivo en Alcoholismo; TEDCA). This test includes three of the cognitive areas that are impaired with alcohol consumption, such as the visual-spatial area, memory and learning, and executive functions [8].

\subsection{Statistical Analysis}

Statistical analyses were performed using IBM SPSS Statistics version 23. All variables were expressed as means (standard deviation) or means and confidence intervals. Data were tested for normality and homogeneity of variances. Paired $t$-tests were used to compare differences between groups. For all tests $p<0.05$ was considered to be statistically significant.

\section{Results}

The final sample included 21 patients over 18 years old (42 eyes in total) and 21 healthy controls (42 eyes in total) paired by age. In both groups, participants were Caucasian males with a mean age of $51.7 \pm 4.6$ for the AUD group and $52.3 \pm 5.3$ for the control group. The best-corrected visual acuities, anterior and posterior segment examinations, intraocular pressure, and pupillary light reflexes were normal for both eyes of all participants. None of the eyes were excluded because of unreliable SD-OCT scans.

The mean initial age for alcohol consumption was $14.57 \pm 2.60$, and the mean age at which AUD patients met the criteria for harmful drinking was $24.14 \pm 6.75$. The mean quantity of alcohol consumption using the SDU was $24.43 \pm 12.51$. Finally, the meantime of abstinence, considering that a 3-month period of abstinence was required for inclusion in this study, was $8.67 \pm 7.25$ months. The mean score on the TEDCA was $11.37 \pm 2.45$ points.

The average macular thickness for the right eye was significantly thinner in AUD patients $(282.30 \pm 11.58 \mu \mathrm{m})$ than in healthy controls $(289.99 \pm 10.79 \mu \mathrm{m})(p=0.032)]$. Similar results were obtained for the left eye (Table 1).

Table 1. Average macular thickness $(\mu \mathrm{m})$.

\begin{tabular}{ccccccc}
\hline Quadrants & $\begin{array}{c}\text { Control Subjects } \\
\boldsymbol{n}=\mathbf{2 1}\end{array}$ & $\begin{array}{c}\text { SD Control } \\
\mathbf{( \pm )}\end{array}$ & $\begin{array}{c}\text { AUD Patients } \\
\boldsymbol{n}=\mathbf{2 1}\end{array}$ & $\begin{array}{c}\text { SD Alcohol } \\
( \pm)\end{array}$ & $\begin{array}{c}\text { Difference } \\
\text { CI }\end{array}$ & $\boldsymbol{p}$ Value \\
\hline Right $(\mu \mathrm{m})$ & 289.99 & 10.79 & 282.30 & 11.58 & 0.71 to 14.67 & $0.032^{*}$ \\
\hline Left $(\mu \mathrm{m})$ & 289.93 & 10.22 & 281.68 & 10.22 & 1.76 to 14.74 & $0.014^{*}$ \\
\hline
\end{tabular}

Mean (SD) value of the macular thickness $(\mu \mathrm{m})$ in each of the $90^{\circ}$ quadrants around the macula of control subjects and alcoholic patients. Confidence intervals for the difference in means (Difference CI). Significance of difference $t$-test: $p$-value. * Statistically significant data $(p<0.05)$.

Macular thickness was lower in main quadrants (superior, inferior, temporal, and nasal) in AUD patients compared to controls, with the exception of central (see Table 2). For a better understanding of the data obtained, we included a box diagram with the values obtained, differentiating each eye and quadrants (Figure 5), which provides complete information on the degree of dispersion of the data and the degree of asymmetry of the distribution in the quadrants set forth above. 
Table 2. Macular thickness $(\mu \mathrm{m})$ in each of the $90^{\circ}$ quadrants around the macula.

\begin{tabular}{|c|c|c|c|c|c|c|}
\hline Quadrants $(\mu \mathrm{m})$ & $\begin{array}{c}\text { Control Subjects } \\
\quad n=21\end{array}$ & $\begin{array}{c}\text { SD Control } \\
( \pm)\end{array}$ & $\begin{array}{c}\text { AUD Patients } \\
n=21\end{array}$ & $\begin{array}{c}\text { SD Alcohol } \\
( \pm)\end{array}$ & Difference CI & $p$ Value \\
\hline \multicolumn{7}{|l|}{ Peripheral superior } \\
\hline Right & 274.86 & 14.57 & 272.29 & 13.71 & -6.25 to 11.40 & 0.559 \\
\hline Left & 276.10 & 16.10 & 272.10 & 12.77 & -5.07 to 11.06 & 0.378 \\
\hline \multicolumn{7}{|l|}{ Superior } \\
\hline Right & 320.10 & 13.02 & 309.19 & 11.25 & 3.31 to 18.50 & $0.006^{*}$ \\
\hline Left & 321.43 & 13.12 & 309.76 & 11.27 & 4.04 to 19.30 & $0.004 *$ \\
\hline \multicolumn{7}{|l|}{ Central } \\
\hline Right & 250.48 & 13.50 & 237.62 & 34.09 & -3.31 to 29.03 & 0.120 \\
\hline Left & 249.33 & 11.72 & 241.29 & 22.05 & -3.27 to 19.41 & 0.150 \\
\hline \multicolumn{7}{|l|}{ Inferior } \\
\hline Right & 318.33 & 12.72 & 307.00 & 13.16 & 3.26 to 19.41 & $0.007 *$ \\
\hline Left & 317.86 & 12.33 & 305.76 & 12.93 & 4.21 to 19.98 & 0.040 * \\
\hline \multicolumn{7}{|l|}{ Peripheral inferior } \\
\hline Right & 267.95 & 18.40 & 260.62 & 13.24 & -2.66 to 17.33 & 0.146 \\
\hline Left & 266.43 & 16.85 & 258.33 & 12.92 & -1.27 to 17.46 & 0.089 \\
\hline \multicolumn{7}{|l|}{ Peripheral temporal } \\
\hline Right & 262.29 & 14.33 & 258.00 & 13.34 & -4.35 to 12.92 & 0.320 \\
\hline Left & 261.19 & 15.05 & 255.90 & 13.39 & -3.60 to 14.17 & 0.236 \\
\hline \multicolumn{7}{|l|}{ Temporal } \\
\hline Right & 308.14 & 13.35 & 298.48 & 13.72 & -1.22 to 18.11 & $0.026^{*}$ \\
\hline Left & 308.10 & 13.22 & 297.10 & 12.95 & 2.84 to 19.16 & 0.010 * \\
\hline \multicolumn{7}{|l|}{ Nasal temporal } \\
\hline Right & 288.14 & 16.44 & 285.29 & 9.67 & -5.55 to 11.27 & 0.497 \\
\hline Left & 287.86 & 14.49 & 283.71 & 8.92 & -3.36 to 11.65 & 0.271 \\
\hline \multicolumn{7}{|l|}{ Nasal } \\
\hline Right & 319.67 & 11.79 & 312.24 & 12.44 & -0.13 to 1499 & 0.054 \\
\hline Left & 321.10 & 10.25 & 311.19 & 12.77 & 2.67 to 17.13 & $0.008^{*}$ \\
\hline
\end{tabular}

At the papilla level, no significant differences were found in the average of each eye (Table 3) nor in any quadrant specifically (Table 4). We also included a box diagram with the values obtained, differentiating each eye and quadrants, for better comparison (Figure 6). As the figure shows, there was a smaller variance of the data than in the case of macular thickness.

Table 3. Average peripapillary RNFL thickness ( $\mu \mathrm{m})$.

\begin{tabular}{ccccccc}
\hline Quadrants & $\begin{array}{c}\text { Control Subjects } \\
\boldsymbol{n = 2 1}\end{array}$ & $\begin{array}{c}\text { SD Control } \\
\mathbf{(} \mathbf{(})\end{array}$ & $\begin{array}{c}\text { AUD Patients } \\
\boldsymbol{n}=\mathbf{2 1}\end{array}$ & $\begin{array}{c}\text { SD Alcohol } \\
\mathbf{( \pm )}\end{array}$ & Difference CI & $\boldsymbol{p}$ Value \\
\hline Right $(\mu \mathrm{m})$ & 101.83 & 15.14 & 101.51 & 12.03 & -8.21 to 8.85 & 0.940 \\
Left $(\mu \mathrm{m})$ & 100.83 & 14.63 & 96.93 & 14.28 & -5.11 to 12.92 & 0.387 \\
\hline
\end{tabular}

Mean (SD) value of the average peripapillary RNFL thickness $(\mu \mathrm{m})$ for each of the $90^{\circ}$ quadrants of the control and patient groups. Confidence intervals for the difference in means (Difference CI). Significance of difference $t$-test: $p$-value. 

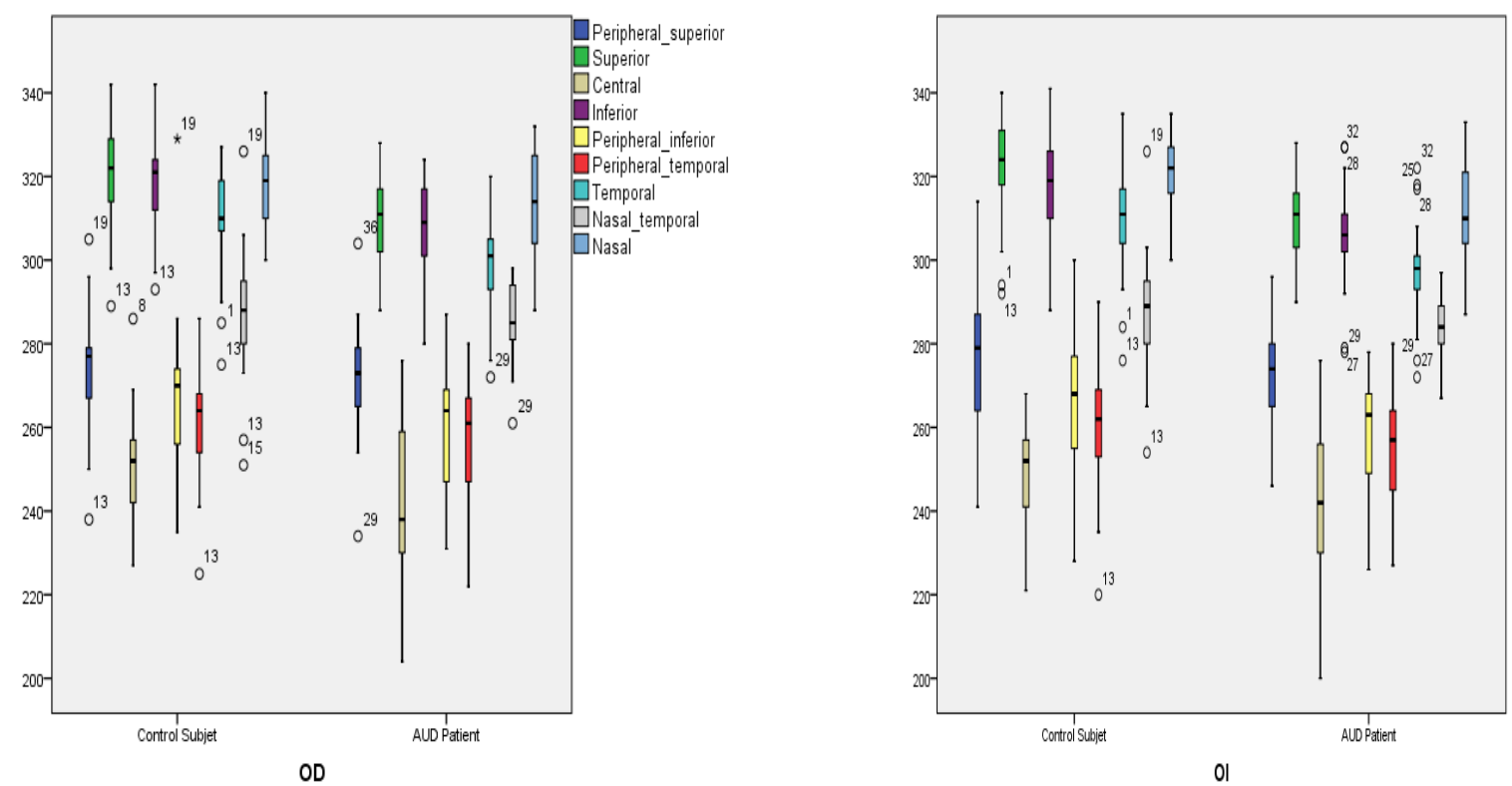

Figure 5. Box diagram corresponding to macular thickness. Values are expressed using median, percentiles, and extreme values.

Table 4. Peripapillary RNFL thickness $(\mu \mathrm{m})$ in each of the $90^{\circ}$ quadrants around the optic disk.

\begin{tabular}{|c|c|c|c|c|c|c|}
\hline Quadrants $(\mu \mathrm{m})$ & $\begin{array}{l}\text { Control Subjects } \\
\quad n=21\end{array}$ & $\begin{array}{l}\text { SD Control } \\
( \pm)\end{array}$ & $\begin{array}{l}\text { AUD Patients } \\
\quad n=21\end{array}$ & $\begin{array}{l}\text { SD Alcohol } \\
( \pm)\end{array}$ & Difference CI & $p$ Value \\
\hline \multicolumn{7}{|l|}{ Superior } \\
\hline Right & 122.57 & 22.16 & 124.05 & 16.10 & -13.56 to 10.6 & 0.806 \\
\hline Left & 125.14 & 20.18 & 120.76 & 23.31 & -9.22 to 17.98 & 0.519 \\
\hline \multicolumn{7}{|l|}{ Inferior } \\
\hline Right & 129.48 & 22.09 & 129.52 & 23.99 & -14.43 to 14.33 & 0.995 \\
\hline Left & 128.62 & 21.09 & 128.86 & 20.18 & -13.11 to 12.64 & 0.970 \\
\hline \multicolumn{7}{|l|}{ Temporal } \\
\hline Right & 72.29 & 72.29 & 67.43 & 67.43 & -1.4 to 11.11 & 0.124 \\
\hline Left & 74.71 & 74.71 & 68.43 & 13.53 & -1.95 to 14.52 & 0.131 \\
\hline \multicolumn{7}{|l|}{ Nasal } \\
\hline Right & 83.00 & 16.60 & 85.05 & 16.34 & -12.32 to 8.22 & 0.689 \\
\hline Left & 74.86 & 15.13 & 69.67 & 17.00 & -4.84 to 15.23 & 0.302 \\
\hline
\end{tabular}

Regarding the nerve fiber layer in the macular and papilla areas, we found no significant differences. At the peripapillary ganglion cell layer (GCC), we found significant differences in all quadrants, with the exception of the superior and superior nasal area, for the right eye. For the left eye we only find differences in the lower quadrant. Finally, in the GCL, we observed that all quadrants were reduced in the AUD patients compared to the controls (Table 5) with the exception of the superior and inferior temporal area, for the left eye. For the right eye we only found differences in the inferior nasal quadrant. 

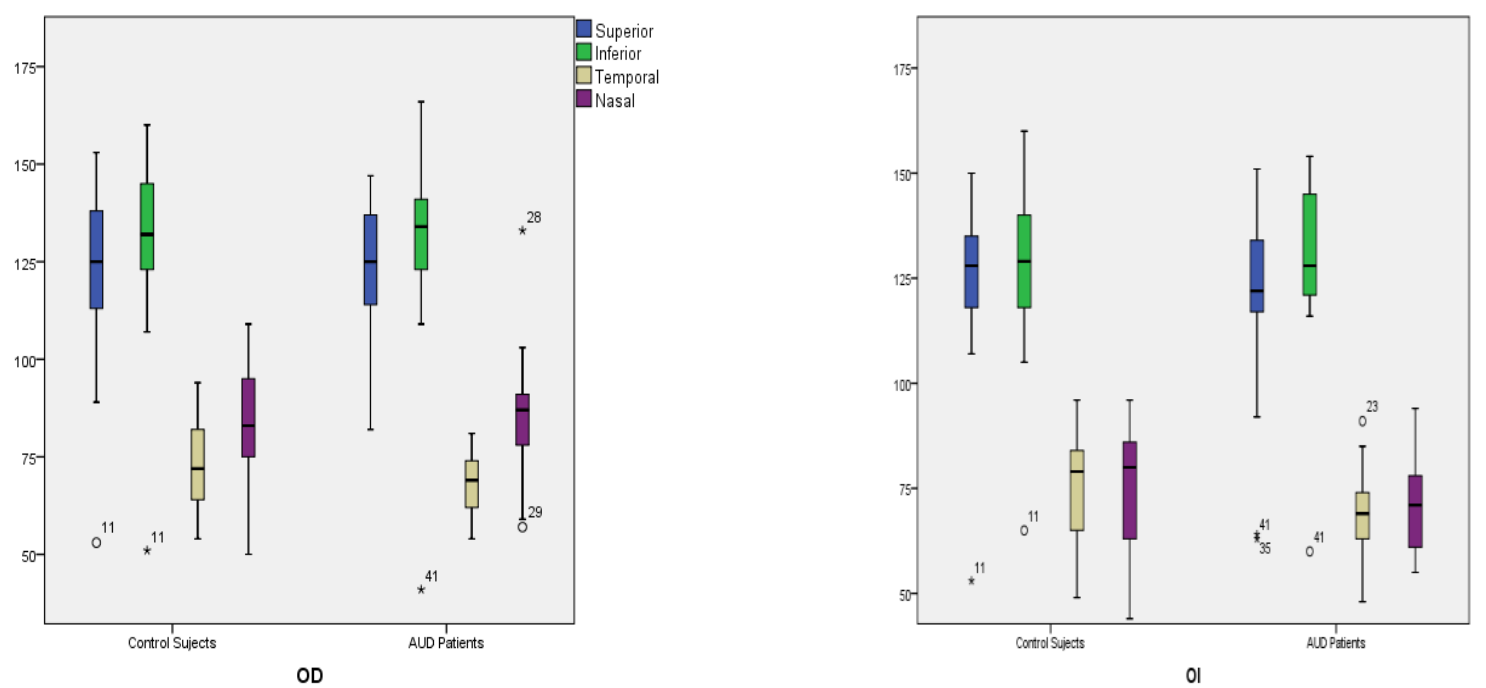

Figure 6. Box diagram corresponding to peripapillary RNFL. Values are expressed using median, percentiles, and extreme values.

Table 5. RNFL macular and GLC thickness $(\mu \mathrm{m})$.

\begin{tabular}{|c|c|c|c|c|c|c|}
\hline Quadrants $(\mu \mathrm{m})$ & $\begin{array}{c}\text { Control Subjects } \\
\quad n=21\end{array}$ & $\begin{array}{c}\text { SD Control } \\
( \pm)\end{array}$ & $\begin{array}{c}\text { AUD Patients } \\
\quad n=21\end{array}$ & $\begin{array}{c}\text { SD Alcohol } \\
( \pm)\end{array}$ & Difference CI & $p$ Value \\
\hline \multicolumn{7}{|l|}{ RNFL macula } \\
\hline Right & 28.97 & 2.20 & 27.77 & 2.13 & -0.16 to 2.54 & 0.081 \\
\hline Left & 28.72 & 2.21 & 27.82 & 2.67 & -0.62 to 2.43 & 0.239 \\
\hline \multicolumn{7}{|l|}{$\mathrm{GLC}++{ }^{1}$} \\
\hline Right & 109.13 & 8.46 & 104.00 & 7.23 & 0.22 to 10.04 & $0.041 *$ \\
\hline Left & 109.33 & 6.53 & 105.12 & 7.77 & -0.27 to 8.68 & 0.065 \\
\hline \multicolumn{7}{|l|}{ GLC $+{ }^{2}$} \\
\hline Right & 74.75 & 5.95 & 71.52 & 5.14 & -0.24 to 6.70 & 0.670 \\
\hline Left & 74.87 & 5.23 & 70.91 & 5.83 & 0.51 to 7.42 & $0.025 *$ \\
\hline
\end{tabular}

${ }^{1}$ Ganglio cell complex (GCC): RNFL + ganglion cell layer (GCL) + inner plexiform layer (IPL). ${ }^{2}$ GLC: RNFL/GLC and IPL/INL (inner nuclear layer). * Statistically significant data $(p<0.05)$.

No significant correlations were found between RNFL thickness and alcohol consumption (using the SDUs) in any of the quadrants explored. However, we did find significant correlations between retinal thickness in the macular area, and the inferior and nasal peripheral areas (see Tables 6 and 7), the nerve, and peripheral temporal and nasal areas (see Tables 8 and 9), and cognitive impairment.

Table 6. Correlation between cognitive impairment and macular area in the inferior peripheral quadrant.

\begin{tabular}{|c|c|c|c|}
\hline & & Inferior Peripheral & TEDCA \\
\hline \multirow{3}{*}{ Inferior peripheral } & Pearson's Correlation & 1 & -0.352 * \\
\hline & Sig. (bilateral) & & 0.035 \\
\hline & $\mathrm{n}$ & 42 & 36 \\
\hline \multirow{3}{*}{ TEDCA } & Pearson's Correlation & $-0.352 *$ & 1 \\
\hline & Sig. (bilateral) & 0.035 & \\
\hline & $\mathrm{n}$ & 36 & 36 \\
\hline
\end{tabular}

* Correlation is significant at the level 0.01 (bilateral). 
Table 7. Correlation between cognitive impairment and macular area at the nasal peripheral quadrant.

\begin{tabular}{|c|c|c|c|}
\hline & & Nasal Peripheral & TEDCA \\
\hline \multirow{3}{*}{ Nasal peripheral } & Pearson's Correlation & 1 & $-0.457^{*}$ \\
\hline & Sig. (bilateral) & & 0.005 \\
\hline & $n$ & 42 & 36 \\
\hline \multirow{3}{*}{ TEDCA } & Pearson's Correlation & $-0.457 *$ & 1 \\
\hline & Sig. (bilateral) & 0.005 & \\
\hline & $n$ & 36 & 36 \\
\hline
\end{tabular}

${ }^{*}$ Correlation is significant at the level 0.01 (bilateral).

Table 8. Correlation between cognitive impairment and the nerve at the temporal peripheral area.

\begin{tabular}{|c|c|c|c|}
\hline & & Temporal Peripheral RNFL & TEDCA \\
\hline \multirow{3}{*}{ Temporal peripheral RNFL } & Pearson's Correlation & 1 & -0.551 * \\
\hline & Sig. (bilateral) & & 0.001 \\
\hline & $n$ & 42 & 36 \\
\hline \multirow{3}{*}{ TEDCA } & Pearson's Correlation & $-0.551 *$ & 1 \\
\hline & Sig. (bilateral) & 0.001 & \\
\hline & $n$ & 36 & 36 \\
\hline
\end{tabular}

* Correlation is significant at the level 0.01 (bilateral).

Table 9. Correlation between cognitive impairment and the nerve at the nasal area.

\begin{tabular}{|c|c|c|c|}
\hline & & Nasal RNFL & TEDCA \\
\hline \multirow{3}{*}{ Nasal RNFL } & Pearson's Correlation & 1 & $0.456^{*}$ \\
\hline & Sig. (bilateral) & & 0.005 \\
\hline & $n$ & 42 & 36 \\
\hline \multirow{3}{*}{ TEDCA } & Pearson's Correlation & $0.456^{*}$ & 1 \\
\hline & Sig. (bilateral) & 0.005 & \\
\hline & $n$ & 36 & 36 \\
\hline
\end{tabular}

${ }^{*}$ Correlation is significant at the level 0.01 (bilateral).

\section{Discussion}

The results of our study show that patients with a history of chronic alcohol consumption exhibit a retinal impairment in all quadrants, even though this impairment does not correlate with the maximum quantity of alcohol consumption calculated by SDUs. However, we found significant correlations between retinal impairment and cognitive impairment.

\subsection{Correlation Between Retinal Thickness and Alcohol Consumption}

In the current research, we found that AUD patients show a statistically significant reduction in the total thickness of the macula and in the GCL in all quadrants.

Findings regarding impairment in the ganglion cell layer indicate a possible axonal impairment. It must be pointed out that impairment caused in the RNFL and in the GCL has been correlated with brain impairment [9-11].

The only study published to date on chronic alcohol consumption and the thickness of the RNFL is one by Ahuja's group [12]. In this study, which included 100 patients who actively consumed alcohol, a reduction in the thickness of the RNFL reaching statistical significance in all quadrants (superior, 
inferior, and temporal) was found when comparing that group to the control group, which was paired by age.

In this study, retinal impairment and severity of alcohol consumption were correlated in patients who were consuming alcohol, and patients who scored over 20 in the AUDIT scale exhibited a greater reduction on the thickness of the RNFL. However, as in our study, these differences did not reach statistical significance.

One possible explanation for this lack of significance in the correlation between alcohol consumption and thickness of the RNFL in our study could be that the quantity of alcohol consumption was subjectively reported by patients during the clinical interviewing, so that alcohol consumption could have been under or overestimated.

Previously, Moura's group published a study that included three patients who consumed alcohol and tobacco [13]. Using OCT, they found that two patients showed a reduction in the retinal thickness of the temporal quadrant.

To the best of our knowledge, this is the first study that explores retinal thickness in abstinent AUD patients, and there is no previous research that has explored its correlation with cognitive tests. For this reason, we consider that our results could be relevant in this field.

Regarding other substance misuse, in a recently published study in which RNFL was assessed using the same technique as in our research, and which included 17 cocaine misusers who were compared to 18 healthy controls, it was found that cocaine misusers exhibited a statistically significant reduction in the thickness of the RNFL in the inferior, superior, and nasal quadrant [5]. This impairment has been correlated with the vasoconstrictor effect that cocaine has on the retinal vessels.

It has been postulated that the retina is an accessible biomarker for some mental disorders, as it derives from the same embryonic layer as the brain. The most frequently studied mental disorder to date has been schizophrenia, followed by bipolar disorder and major depressive disorder, in which no impairments have been found [7].

Within mental disorders, several studies carried out mainly in the schizophrenic [14-19] and bipolar $[20,21]$ populations, and using the OCT test, have shown changes in the retinal nerve fiber.

\subsection{Correlation Between Retinal Thickness and Cognitive Impairment}

It has been estimated that between 50 and $70 \%$ of patients who suffer from an AUD exhibit cognitive impairment to some extent [22,23]. These impairments mainly affect anterograde and retrograde memory, visual-spatial thinking, cognitive skills, and attention [24].

The use of neuroimaging techniques has revealed structural and functional changes in the brains of alcoholic patients [22]. To the best of our knowledge, no studies to date have been carried out using OCT to assess the cognitive impairment caused by alcohol consumption. In the present study, we found significant differences in the macular area and in the nerve, which correlated with a more intensive cognitive impairment as assessed by the TEDCA scale.

Although there are no previous studies in which retinal impairment has been correlated with cognitive impairment caused by alcohol consumption, multiple studies have described these same findings regarding retinal thickness in other illnesses in which cognitive impairment presents, such as Alzheimer's disease. Using the same technique as in our study, OCT, a reduction in the RNFL was found when comparing patients to the control group. In this way, OCT has been proposed as non-invasive for early diagnosis [25].

In recent meta-analyses [26,27] it was concluded that reductions in the RNFL were significantly higher in patients diagnosed with Alzheimer's disease or mild cognitive impairment (MCI) compared to controls. Some studies report that these findings affect all the retinal quadrants, whereas others conclude that only specific areas are impaired, with some studies focusing on the superior quadrants and others on the inferior quadrants [28].

As in our sample, there are also some studies that have found a significant correlation in the macular area. More specifically, in a study that used the mini-mental state examination (MMSE) to 
assess the severity of cognitive impairment, a significant correlation was found between scores on the MMSE and the reduction in the volume of the macula [29].

Regarding specific changes within the retina, a huge field of research remains open, as the reason why some specific quadrants, the macula or optic nerve, are more severely impaired compared to others has not yet been completely explained.

During the last few years, several studies carried out on patients suffering from different neurodegenerative diseases such as sclerosis $[9,30,31]$ have found reductions in the RNLF of the retina. However, to the best of our knowledge, our study is unique because no other studies have been carried out to date comparing the thickness of the different layers of the retina in patients with AUD.

A limitation of this study is the small sample size, which limits the generalization of our results. This fact could explain the difference in statistical significance in certain quadrants and between the two eyes of the study groups. Another limitation of the study is that there were no variables such as diet or water intake that may be related to changes in the retina. However, as OCT is an objective and easily quantified technique, the doors remain open to replicate our findings in future studies.

\section{Conclusions}

In conclusion, we have found that patients with AUD show a statistically significant reduction in the total thickness of the macula and in the ganglion cell layer in the principal quadrants. In the RNFL of the macula and peripapillary, we did not find significant differences.

Author Contributions: All authors made contributions to this work. Conceptualization, F.L.-M., F.J.P.-M, and F.A.-H.; Clinical sample, S.Á.-S., F.A.-H., and M.M.-M.; Optometrist examiner, F.J.P.-M., P.N.-C., and I.R.-M.; Writing-Original Draft Preparation, S.Á.-S. and M.M.-M.; Writing-Review and Editing, F.A.-H., F.J.P.-M., G.R., and F.L.-M.; Supervision, F.A.-H., F.J.P.-M., G.R., and F.L.-M.; Funding Acquisition, F.L.-M. and F.J.P.-M.

Funding: This work was supported by grants from the Universidad Camilo José Cela (Neuro-Ret project, 2017-2018) and Centro Óptico Montero, Madrid, Spain.

Conflicts of Interest: The authors declare no conflict of interest.

\section{Glossary}

$\begin{array}{ll}\text { AUD } & \text { Alcohol use disorders } \\ \text { CNS } & \text { Central nervous system } \\ \text { GCL } & \text { Ganglion cell layer } \\ \text { GLC+ } & \text { Retina layer between RNFL/GLC and IPL/INL } \\ \text { GLC++ } & \text { Retina layer between ILM and IPL/INL } \\ \text { ILM } & \text { Inner limiting membrane } \\ \text { INL } & \text { Inner nuclear layer } \\ \text { IPL } & \text { Inner plexiform layer } \\ \text { IQV } & \text { Image quality value } \\ \text { MMSE } & \text { Mini-mental state examination } \\ \text { OCT } & \text { Optical coherence tomography } \\ \text { RNFL } & \text { Macular retina layer between ILM and RNFL/GCL } \\ \text { SD-OCT } & \text { Spectral domain optical coherence tomography } \\ \text { SDU } & \text { Standard drinking unit } \\ \text { TEDCA } & \text { Cognitive Impairment in Alcoholic Population Test } \\ \text { WHO } & \text { World Health Organization }\end{array}$

\section{References}

1. WHO. Global Status Report on Alcohol and Health 2018; World Health Organisation: Geneva, Switzerland, 2018.

2. Erdozain, A.M.; Morentin, B.; Bedford, L.; King, E.; Tooth, D.; Brewer, C.; Wayne, D.; Johnson, L.; Gerdes, H.K.; Wigmore, P.; et al. Alcohol-related brain damage in humans. PLoS ONE 2014, 9, e93586. [CrossRef] [PubMed]

3. Soler Gonzalez, C.; Balcells Olivero, M.; Gual Sole, A. Alcohol related brain damage. State of the art and a call for action. Adicciones 2014, 26, 199-207. [PubMed] 
4. London, A.; Benhar, I.; Schwartz, M. The retina as a window to the brain-from eye research to, C.N.S disorders. Nat. Rev. Neurol. 2013, 9, 44-53. [CrossRef] [PubMed]

5. Gemelli, H.; Fidalgo, T.M.; Gracitelli, C.P.B.; de Andrade, E.P. Retinal nerve fiber layer analysis in cocaine users. Psychiatry Res. 2019, 271, 226-229. [CrossRef]

6. Schwitzer, T.; Schwan, R.; Bubl, E.; Lalanne, L.; Angioi-Duprez, K.; Laprevote, V. Looking into the brain through the retinal ganglion cells in psychiatric disorders: A review of evidences. Prog. Neuropsychopharmacol. Biol. Psychiatry 2017, 76, 155-162. [CrossRef]

7. Garcia-Portilla, M.P.; Garcia-Alvarez, L.; de la Fuente-Tomas, L.; Velasco-Iglesias, Á.; Sáiz, P.A.; González-Blanco, L.; Bobes Bascarán, M.T.; Baamonde, B.; Alcalde, I.; Merayo-Lloves, J.; et al. Could structural changes in the retinal layers be a new biomarker of mental disorders? A systematic review and thematic synthesis. Rev. Psiquiatr. Salud Ment. 2019, 12, 116-129. [CrossRef]

8. Jurado-Barba, R.; Martinez, A.; Sion, A.; Álvarez-Alonso, M.J.; Robles, A.; Quinto-Guillen, R.; Rubio, G. Development of a screening test for cognitive impairment in alcoholic population: TEDCA. Actas Esp. Psiquiatr. 2017, 45, 201-217.

9. Gordon-Lipkin, E.; Chodkowski, B.; Reich, D.S.; Smith, S.A.; Pulicken, M.; Balcer, L.J.; Frohman, E.M.; Cutter, G.; Calabresi, P.A. Retinal nerve fiber layer is associated with brain atrophy in multiple sclerosis. Neurology 2007, 69, 1603-1609. [CrossRef]

10. Mutlu, U.; Ikram, M.K.; Roshchupkin, G.V.; Bonnemaijer, P.W.M.; Colijn, J.M.; Vingerling, J.R.; Niessen, W.J.; Ikram, M.A.; Klaver, C.C.W.; Vernooij, M.W. Thinner retinal layers are associated with changes in the visual pathway: A population-based study. Hum. Brain Mapp. 2018, 39, 4290-4301. [CrossRef]

11. Ascaso, F.J.; Cruz, N.; Modrego, P.J.; López-Anton, R.; Santabárbara, J.; Pascual, L.F.; Lobo, A.; Cristóbal, J.A. Retinal alterations in mild cognitive impairment and Alzheimer's disease: An optical coherence tomography study. J. Neurol. 2014, 261, 1522-1530. [CrossRef]

12. Ahuja, S.; Kumar, P.S.; Kumar, V.P.; Kattimani, S.; Akkilagunta, S. Effect of chronic alcohol and tobacco use on retinal nerve fibre layer thickness: A case-control study. BMJ Open Ophthalmol. 2017, 1, e000003. [CrossRef] [PubMed]

13. Moura, F.C.; Monteiro, M.L. Evaluation of retinal nerve fiber layer thickness measurements using optical coherence tomography in patients with tobacco-alcohol-induced toxic optic neuropathy. Indian J. Ophthalmol. 2010, 58, 143-146. [CrossRef] [PubMed]

14. Chu, E.M.; Kolappan, M.; Barnes, T.R.; Joyce, E.M.; Ron, M.A. A window into the brain: An in vivo study of the retina in schizophrenia using optical coherence tomography. Psychiatry Res. 2012, 203, 89-94. [CrossRef] [PubMed]

15. Lee, W.W.; Tajunisah, I.; Sharmilla, K.; Peyman, M.; Subrayan, V. Retinal nerve fiber layer structure abnormalities in schizophrenia and its relationship to disease state: Evidence from optical coherence tomography. Investig. Ophthalmol. Vis. Sci. 2013, 54, 7785-7792. [CrossRef] [PubMed]

16. Gagne, A.M.; Hebert, M.; Maziade, M. Revisiting visual dysfunctions in schizophrenia from the retina to the cortical cells: A manifestation of defective neurodevelopment. Prog. Neuropsychopharmacol. Biol. Psychiatry 2015, 62, 29-34. [CrossRef] [PubMed]

17. Celik, M.; Kalenderoglu, A.; Sevgi Karadag, A.; Bekir Egilmez, O.; Han-Almis, B.; Simsek, A. Decreases in ganglion cell layer and inner plexiform layer volumes correlate better with disease severity in schizophrenia patients than retinal nerve fiber layer thickness: Findings from spectral optic coherence tomography. Eur. Psychiatry 2016, 32, 9-15. [CrossRef]

18. Yilmaz, U.; Kücük, E.; Ülgen, A.; Özköse, A.; Demircan, S.; Ulusoy, D.M.; Zararsız, G. Retinal nerve fiber layer and macular thickness measurement in patients with schizophrenia. Eur. J. Ophthalmol. 2016, 26, 375-378. [CrossRef]

19. Mehraban, A.; Samimi, S.M.; Entezari, M.; Seifi, M.H.; Nazari, M.; Yaseri, M. Peripapillary retinal nerve fiber layer thickness in bipolar disorder. Graefe's Arch. Clin. Exp. Ophthalmol. 2016, 254, 365-371. [CrossRef]

20. Kalenderoglu, A.; Sevgi-Karadag, A.; Celik, M.; Egilmez, O.B.; Han-Almis, B.; Ozen, M.E. Can the retinal ganglion cell layer (GCL) volume be a new marker to detect neurodegeneration in bipolar disorder? Compr. Psychiatry 2016, 67, 66-72. [CrossRef]

21. Glass, J.M.; Buu, A.; Adams, K.M.; Nigg, J.T.; Puttler, L.I.; Jester, J.M.; Zucker, R.A. Effects of alcoholism severity and smoking on executive neurocognitive function. Addiction 2009, 104, 38-48. [CrossRef] 
22. Sachdeva, A.; Chandra, M.; Choudhary, M.; Dayal, P.; Anand, K.S. Alcohol-Related Dementia and Neurocognitive Impairment: A Review Study. Int. J. High Risk Behav. Addict. 2016, 5, e27976. [CrossRef] [PubMed]

23. Frías-Torres, C.; Moreno-España, J.; Ortega, L.; Barrio, P.; Gual, A.; Teixidor López, L. Remediation therapy in patients with alcohol use disorders and neurocognitive disorders: A Pilot Study. Adicciones 2018, 30, $93-100$. [CrossRef] [PubMed]

24. Kwon, J.Y.; Yang, J.H.; Han, J.S.; Kim, D.G. Analysis of the Retinal Nerve Fiber Layer Thickness in Alzheimer Disease and Mild Cognitive Impairment. Korean J. Ophthalmol. 2017, 31, 548-556. [CrossRef] [PubMed]

25. Coppola, G.; Di Renzo, A.; Ziccardi, L.; Martelli, F.; Fadda, A.; Manni, G.; Barboni, P.; Pierelli, F.; Sadun, A.A.; Parisi, V. Optical coherence tomography in Alzheimer's disease: A meta-analysis. PLoS ONE 2015, 10. [CrossRef] [PubMed]

26. Thomson, K.L.; Yeo, J.M.; Waddell, B.; Cameron, J.R.; Pal, S. A systematic review and meta-analysis of retinal nerve fiber layer change in dementia, using optical coherence tomography. Alzheimers Dement. (Amst.) 2015, 1, 136-143. [CrossRef] [PubMed]

27. Liao, H.; Zhu, Z.; Peng, Y. Potential Utility of Retinal Imaging for Alzheimer's Disease: A Review. Front. Aging Neurosci. 2018, 10, 188. [CrossRef]

28. Moreno-Ramos, T.; Benito-Leon, J.; Villarejo, A.; Bermejo-Pareja, F. Retinal nerve fiber layer thinning in dementia associated with Parkinson's disease, dementia with Lewy bodies, and Alzheimer's disease. J. Alzheimers Dis. 2013, 34, 659-664. [CrossRef]

29. Iseri, P.K.; Altinas, O.; Tokay, T.; Yuksel, N. Relationship between cognitive impairment and retinal morphological and visual functional abnormalities in Alzheimer disease. J. Neuroophthalmol. 2006, 26, 18-24. [CrossRef]

30. Gundogan, F.C.; Demirkaya, S.; Sobaci, G. Is optical coherence tomography really a new biomarker candidate in multiple sclerosis?-A structural and functional evaluation. Investig. Ophthalmol. Vis. Sci. 2007, 48, 5773-5781. [CrossRef]

31. Satue, M.; Rodrigo, M.J.; Otin, S.; Bambo, M.P.; Fuertes, M.I.; Ara, J.R.; Martin, J.; Polo, V.; Larrosa, J.M.; Pablo, L.; et al. Relationship between Visual Dysfunction and Retinal Changes in Patients with Multiple Sclerosis. PLoS ONE 2016, 11, e0157293. [CrossRef] 